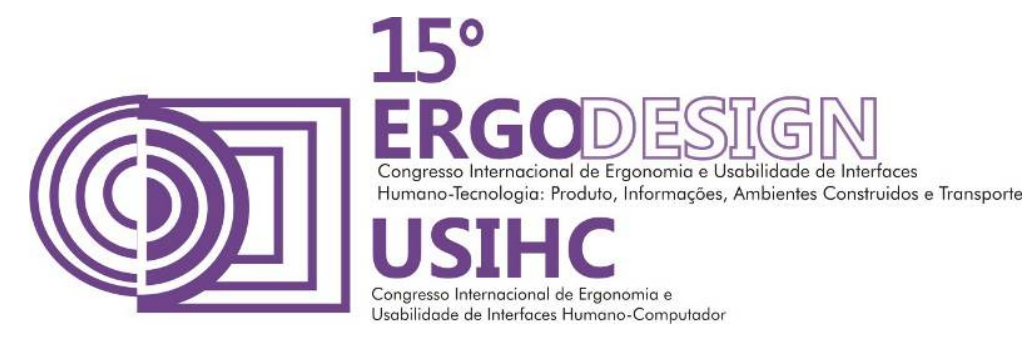

\title{
ROTAS SEGURAS: A QUALIDADE ESPACIAL NO ENTORNO DE ÁREAS ESCOLARES PARA USUÁRIOS DE TRANSPORTE PÚBLICO
}

\author{
PRADO, Bruna de Brito (1); \\ MAGAGNIN, Renata Cardoso (2) \\ (1) Universidade Estadual Paulista, Mestranda \\ e-mail: bruna@faac.unesp.br \\ (2) Universidade Estadual Paulista, Profa. Dra. \\ e-mail: magagnin@faac.unesp.br
}

\begin{abstract}
RESUMO
Este artigo apresenta a avaliação da qualidade espacial, para usuários de transporte público, no entorno de uma escola, localizada na cidade de Bauru (SP - Brasil); a partir da aplicação de alguns indicadores de microacessibilidade relacionados ao conforto e segurança dos usuários da escola. Multi-métodos foram utilizados para avaliar a qualidade da microacessibilidade dos usuários. Os resultados mostram que os indicadores utilizados são eficientes para a identificação de problemas e podem auxiliar os gestores locais no planejamento e monitoramento da qualidade espacial no entorno de áreas escolares; e contribuir para a formulação de políticas municipais sobre este tema.
\end{abstract}

\begin{abstract}
This paper presents the assessment of spatial quality for public transport users, in the surrounding of a school located in the city of Bauru (SP - Brazil); from the application of some microacessibilidade indicators related to the comfort and safety of school users. Multi-methods were used to assess the microaccessibility quality of users. The results show that the indicators used are effective to identify problems and can assist local managers in planning and monitoring the spatial quality in the surrounding of school areas; and contribute to the formulation of municipal policies on this topic.
\end{abstract}

\section{INTRODUÇÃO}

As viagens a pé são alternativas importantes a serem consideradas e incentivadas para os deslocamentos nas áreas urbanas, entretanto para tornar essa alternativa viável, é necessário que os espaços urbanos destinados ao uso do pedestre, em particular as calçadas, apresentem um nível de qualidade adequado (FERREIRA E SANCHES, 2007).

O Decreto Federal 5.296/2004 define a acessibilidade como: “a condição para utilização, com segurança e autonomia, total ou assistida, dos espaços, mobiliários e equipamentos urbanos, das edificações, dos serviços de transporte e dos dispositivos, sistemas e meios de comunicação e informação" (BRASIL, 2004). Litman (2008) define a acessibilidade como a 


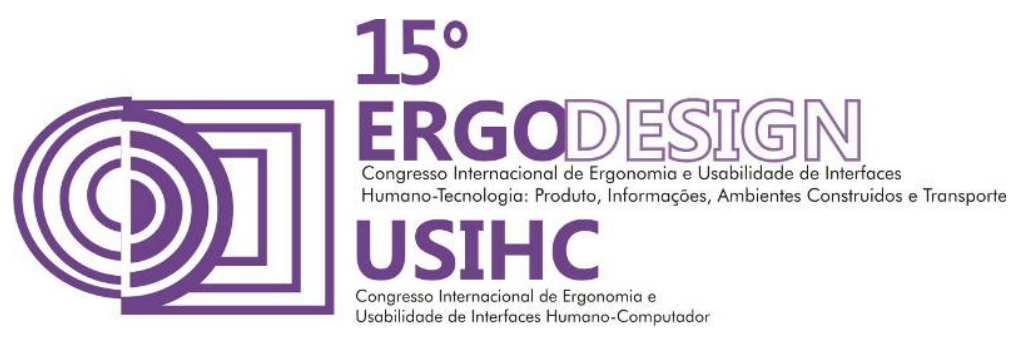

capacidade de atingir bens, serviços, atividades ou destinos desejados. O autor ainda observa que ela pode ser avaliada através dos seguintes elementos: tempo (custo), dinheiro, conforto, segurança. Além desses elementos, ele estabelece três níveis de avaliação da acessibilidade: i) micro-escala, ii) escala regional e iii) escala inter-regional. Neste artigo é adotado, o primeiro conceito, a micro-escala, que também é conhecida como microacessibilidade (LITMAN, 2008).

A microacessibilidade pode ser "afetada pela qualidade das condições físicas dos pedestres, pela proximidade e agrupamento de atividades, e pela infraestrutura viária ofertada" (LITMAN, 2008). Bianchi (2011) complementa esta definição afirmando que a microacessibilidade está relacionada: ao tempo de acesso aos veículos, e ao tempo de acesso aos destinos em deslocamentos a pé. No entanto, o autor diz que outros aspectos complementares devem ser analisados como: a política de estacionamento, os pontos de acesso ao transporte público, a configuração do próprio ambiente de circulação e as condições de conforto e segurança na travessia das vias públicas.

As travessias, denominadas por Campêlo (2011) como conexões, juntamente com as calçadas formam o sistema viário do pedestre cuja infraestrutura ofertada nos espaços físicos tem uma influência direta na mobilidade realizada pelo modo a pé (CAMPÊLO, 2011). A calçada é um dos principais elementos na análise da acessibilidade urbana destinada aos pedestres e aos usuários dos demais meios de transporte, que as utilizam como complementação de seu trajeto. Em alguns casos a interrupção ou descontinuidade da calçada, a falta de conexões ou a ausência de faixa de pedestre, pode ocasionar conflitos com outros modos de transportes, proporcionando insegurança ao pedestre (CAMPÊLO, 2011).

A norma técnica brasileira de acessibilidade (NBR 9050) define o termo rota acessível como "o trajeto contínuo, desobstruído e sinalizado, que conecta os ambientes externos, ou internos, de espaços e edificações, e que pode ser utilizada de forma autônoma e segura por todas as pessoas, inclusive por aquelas com deficiência. A rota acessível externa pode incorporar estacionamentos, calçadas rebaixadas, faixas de travessia de pedestres, rampas, etc." (ABNT, 2004). A partir desta definição é possível afirmar que cada pedestre utiliza um determinado trajeto ou rota que considera mais acessível ou seguro; dependendo de seus objetivos e/ou dos meios de transportes utilizados e, em função das características inerentes ao espaço voltado à circulação (CAMPÊLO, 2011).

De acordo com Campêlo (2011) "uma rota só é classificada como acessível se apresentar, além das características de continuidade e sinalização, a inexistência de barreiras ou impedâncias que caracteriza o trajeto desobstruído de qualquer interferência na circulação dos pedestres". Neste sentido, o piso das calçadas não deve apresentar desníveis, a superfície deve ser regular, antiderrapante e sem obstáculos, os materiais utilizados no piso devem seguir padrões apropriados ao tráfego de pessoas (ABNT, 2004; MAGAGNIN, 2009).

No que se refere à segurança das rotas no entorno de áreas escolares, a literatura nacional e internacional, tem mostrado que há poucos estudos que consideram a criança e o adolescente como público alvo na avaliação das rotas entre os pontos de parada e o edifício escolar. Pesquisas internacionais têm utilizado como referência a definição do termo "criança" dada pela UNICEF (1989) "todo ser humano menor de dezoito anos, salvo se nos termos da lei que lhe for aplicável, atingir a maioridade mais cedo." Essa definição também é adotada nessa pesquisa. Entre as pesquisas nacionais e internacionais relevantes que analisaram o percurso da criança 


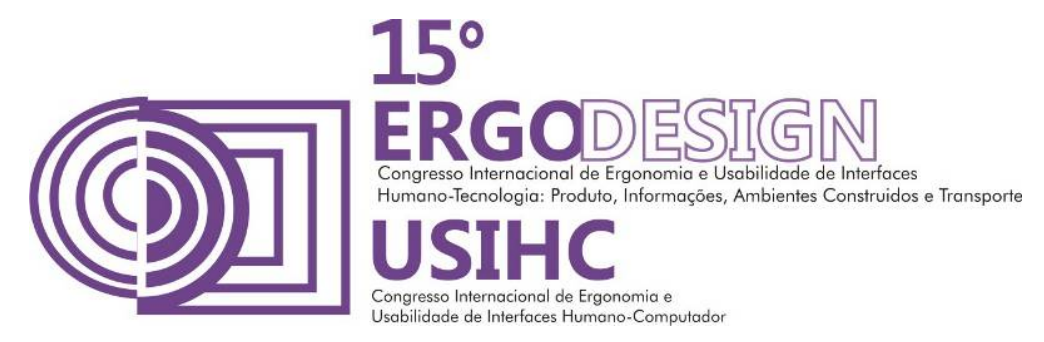

até a escola utilizando diferentes modos de transporte são: Müller e Arruda (2013); Mendonza et al. (2012); Collins \& Kearns (2005); Stewart et al. (2012); Yeung et all (2008); Ipingbemi \& Aiworo (2013). No entanto, estas pesquisas estão relacionadas, em sua maioria, com a definição e/ou aplicação de novos métodos seguros de levar e buscar crianças à escola ou determinando fatores que influenciam a escolha do modo de transporte utilizado para esse percurso, não relacionando-se diretamente ao conforto e segurança de infraestrutura das rotas entre o modo de transporte escolhido e seu destino final, a escola.

Neste contexto, este artigo busca contribuir com a proposição da avaliação por um sistema de indicadores que permite analisar a microacessibilidade em rotas estabelecidas entre pontos de parada do transporte público e a escola, considerando o conforto e a segurança dos pedestres relacionados às calçadas.

\section{2. ÁREA DE ESTUDO}

A Escola Estadual Christino Cabral está localizada na região sul da cidade de Bauru, cidade de porte médio localizada na região centro-oeste do Estado de São Paulo (Figura 1). O município possui uma população de aproximadamente 344 mil habitantes, distribuída em um território de $668 \mathrm{~km}^{2}$ (IBGE, 2014).

A escola possui alunos do Ensino Fundamental II, correspondente ao intervalo do $6^{\circ}$ ao $9^{\circ}$ ano (faixa etária de 11 a 14 anos) e Ensino Médio (faixa etária de 15 aos 17 anos). O Ensino Fundamental é composto por 18 classes (com 543 alunos) e o Ensino Médio por 23 classes (782 alunos), totalizando 1325 alunos que utilizam as calçadas, no entorno da escola, em complementação as suas viagens (trajetos) diárias à escola.

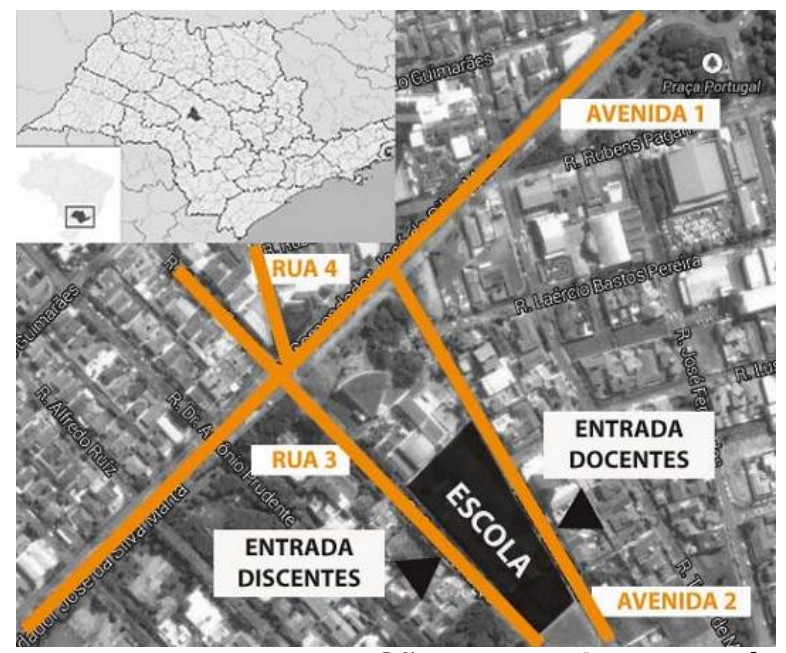

Figura 1 - Localização de Bauru no Estado de São Paulo e imagem aérea do entorno da Escola Estadual Christino Cabral. Fonte: Wikipedia e Google Maps, adaptado pelos autores, 2014.

A entrada dos pedestres discentes nesta escola é realizada pela Rua 3 e a dos docentes e visitantes pela Avenida 2 (Figura 1). A entrada de discentes ocorre em uma rua local, porém com fluxo de veículos considerável. A entrada de docentes está localizada em uma avenida de tráfego mais intenso, entretanto esse acesso à escola é realizado exclusivamente com 


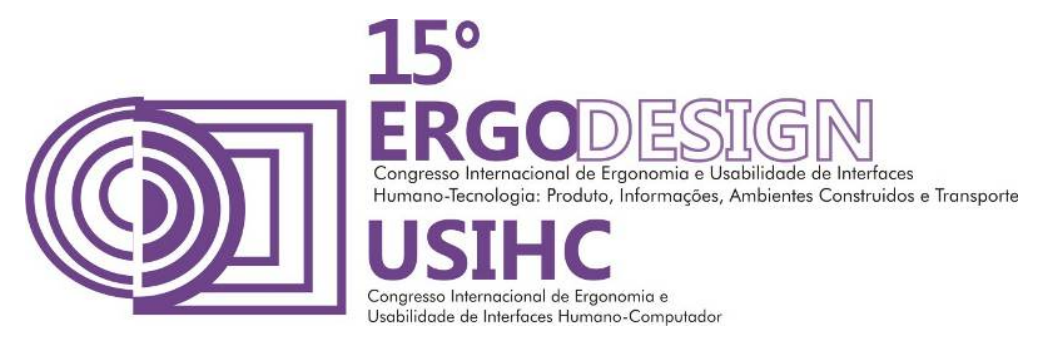

transporte individual motorizado.

\section{METODOLOGIA}

Para a escolha da escola analisada foram considerados os seguintes aspectos: i) localização e ii) presença de pontos de parada próximos a escola. Para a definição das rotas a serem analisadas foram realizadas consultas as ferramentas do Google StreetView, e do site "Seu ônibus online" disponível no site da Transurb Bauru - Associação das empresas de transporte coletivo urbano de Bauru. A formulação de Indicadores de microacessibilidade urbana para avaliar a qualidade espacial das calçadas do entorno de áreas escolares teve como referência os estudos desenvolvidos por Magagnin et al. (2012); Ferreira e Sanches (2007), Keppe Junior (2007), Brasil (2007), entre outros. Para esta avaliação foram adotados métodos e técnicas qualitativas para coleta e análise dos dados. A coleta de dados envolveu trabalho de campo, através da realização de observações in loco e levantamento fotográfico e métrico.

Para a avaliação da qualidade espacial das calçadas no entorno da área escolar foram adotados os seguintes Indicadores de microacessibilidade: Qualidade de Conforto (Largura efetiva, Tipo de piso - escorregadio, Estado de conservação da superfície do piso, Inclinação longitudinal, Inclinação transversal, Desnível); Qualidade da Segurança da Calçada (Iluminação, Arborização e Mobiliário Urbano - calçadas obstruídas por mobiliário urbano); e Qualidade de Segurança durante a Travessia (Sinalização horizontal, Sinalização vertical, Rampa, Visão de aproximação dos veículos na travessia, Semáforo para pedestres, Tempo de semáforo).

\section{ANÁLISE DOS DADOS}

Nesta seção é apresentada a análise dos resultados obtidos na aplicação dos Indicadores de microacessibilidade propostos. A análise iniciou com um estudo da localização dos pontos de parada de ônibus existentes no entorno da Escola Estadual Christino Cabral (Figura 2) e com a definição das linhas de ônibus que tem como destino estes pontos.

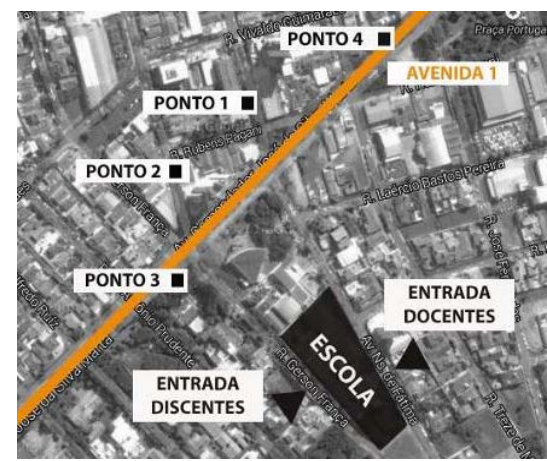

Figura 2 - Localização da escola, entrada de docentes, discentes e localização dos pontos de parada do entorno. Fonte: Adaptado do Google Maps, 2014

No entorno da escola há quatro pontos de parada de ônibus (ver Figura 2), sendo que dois deles (Pontos 3 e 4) estão localizados na Avenida 1, e outros dois (Pontos 1 e 2), em duas ruas perpendiculares à Avenida 1. Estes quatro pontos de parada são servidos por oito linhas do 


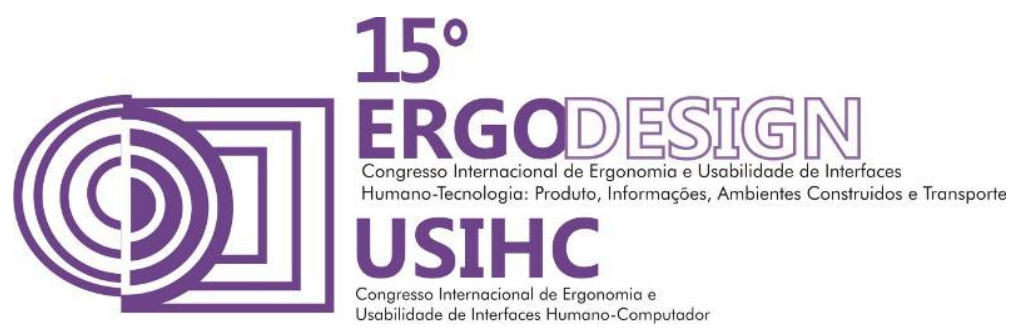

sistema de transporte público urbano, segundo dados da Emdurb - Empresa de desenvolvimento urbano e rural de Bauru (2014): Linha L1 alimenta o Ponto 3; as Linhas L2 e L4 alimentam os Pontos 3 e 4; as Linhas L3, L5, L7 e L8 alimentam os Pontos 1 e 2; a Linha L6 alimenta o Ponto 2.

Ao analisar os dados das oito linhas que passam pelos quatro Pontos de Parada foi possível constatar que metade das linhas de ônibus que tem como destino esta região da cidade tem como parada intermediária ou final os Pontos 1 e 2. Uma das linhas tem como ponto final 0 Ponto 2 e o restante das linhas estão associadas aos Pontos 3 e 4 . Em todos os casos identificamos que uma mesma linha possui dois pontos de parada próximos a região da Escola estudada.

A partir desta informação inicial, foi realizada uma pesquisa para identificar no trajeto de cada linha de transporte público qual ponto de parada estava mais próximo para embarque e desembarque dos discentes e assim analisar a microacessibilidade nestes trajetos.
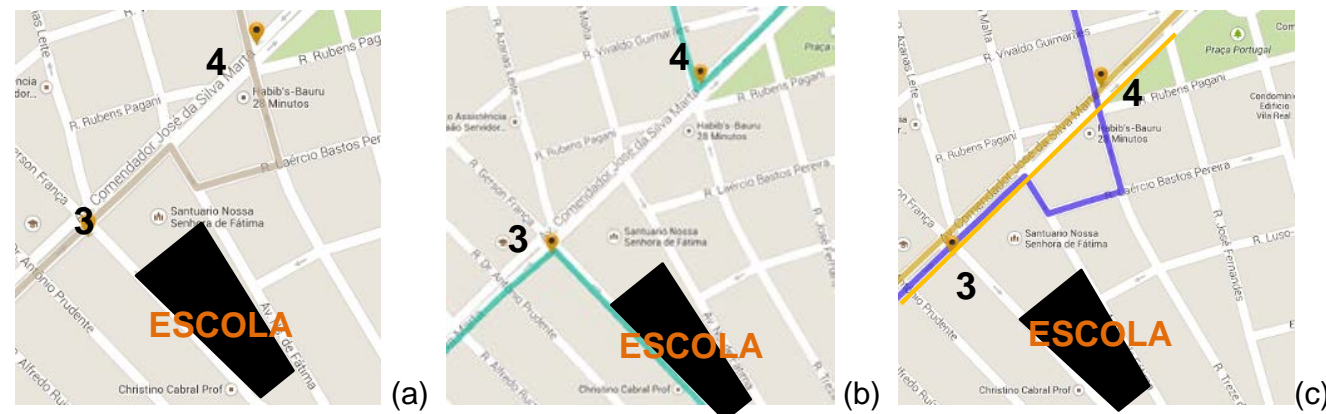

Figura 3 - Trajeto das linhas do sistema de transporte público no entorno da escola: (a) L1; (b) L2;

(c) L4 (amarelo -ida e roxo-volta).

Fonte: adaptado http://tdmax.transurbbauru.com.br/ITSInformativo/Home/Index

O primeiro grupo de linhas de transporte público analisado correspondeu às Linhas L1, L2 e L4 (Figura 3a, 3b e 3c). Nas Linhas L1 e L2 o Ponto 3 é acessado anteriormente ao Ponto 4, e o primeiro é o ponto mais próximo para acessar a escola pelo modo a pé. Na linha L4, o Ponto 4 é acessado na ida por uma rota (em amarelo, Figura 3c), enquanto o Ponto 3 é acessado na volta por outra rota (em roxo, Figura 3c). Como o Ponto 3 é o ponto de parada mais próximo da escola, ele é o mais movimentado para o embarque e desembarque de passageiros quando comparado com o Ponto 4, dessa forma, esse último será desconsiderado para esta análise.
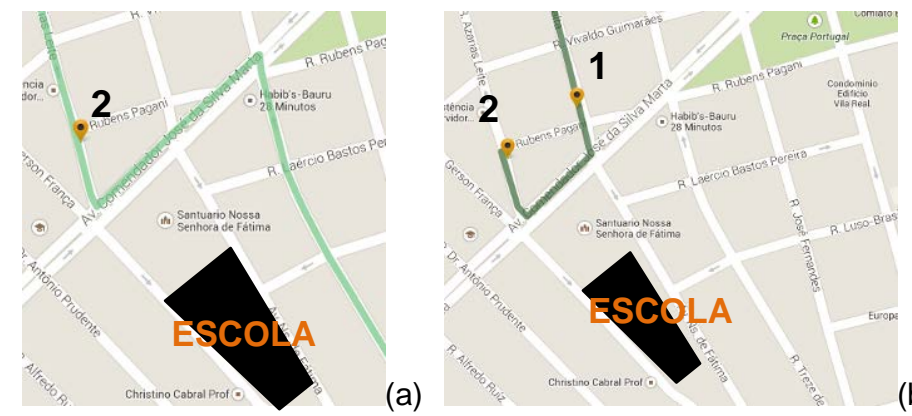


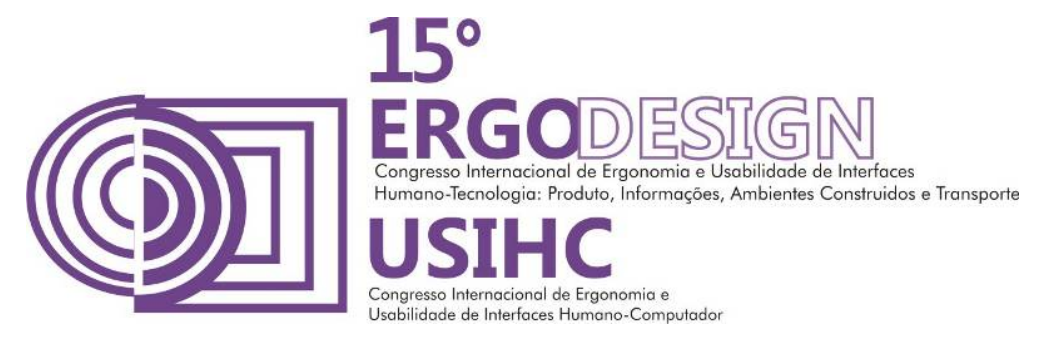

Figura 4 - Trajeto das linhas do sistema de transporte público no entorno da escola: (a) L6 e (b) L3, L5, L7 e L8. Fonte: http://tdmax.transurbbauru.com.br/ITSInformativo/Home/Index

O segundo grupo analisado consistiu nas linhas L3, L5, L7 e L8 (Figuras 4a e 4b). Neste grupo, o Ponto 1 é sempre um ponto de parada intermediário e anterior ao Ponto 2, pois este último funciona como ponto final na maior parte das linhas analisadas, inclusive na linha L6. Como o Ponto 2 é mais próximo da escola, ele foi considerado na análise e o Ponto 1 desconsiderado.

Em função das análises acima apresentadas, que foram baseadas na proximidade dos pontos de parada em relação à escola, apenas os pontos de parada 2 e 3 serão analisados a seguir.

O primeiro percurso analisado, denominado de Rota $R 1$, correspondeu ao percurso compreendido entre o Ponto de Parada 2 e a Escola (Figura 5). A partir desse Ponto, o usuário do transporte público deve atravessar a Avenida 1 para chegar à calçada que acessa a escola. O percurso denominado Rota R2 está compreendido entre o Ponto 3 e a escola (Figura 5). Neste trajeto o usuário do transporte público deverá utilizar a mesma calçada até chegar em frente da escola e só então realizar a travessia da Rua 3.

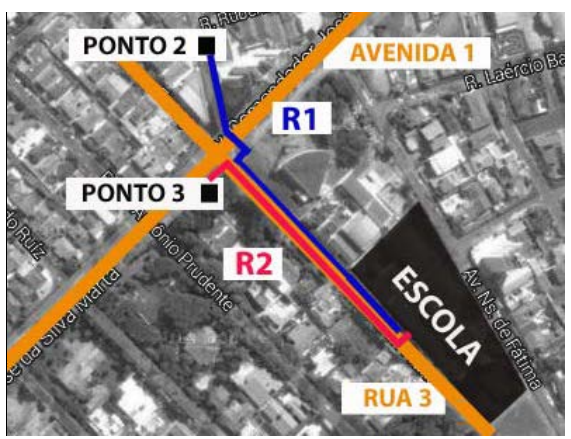

Figura 5 - Trajetos analisados: Pontos 2 e 3 até a escola Fonte: Adaptado do Google Maps

A partir da definição das rotas, iniciou-se o processo de análise da tipologia das calçadas encontradas nestes dois trajetos. Foram encontradas seis tipologias, as Figuras $6 a, 6 b, 6 c$ e $6 d$ correspondem às calçadas encontradas na Rota $R 1$ e a Figura 6e na Rota R2. As Figuras 7a a 7 apresentam o levantamento fotográfico realizado ao longo da Rota $R 1$. 

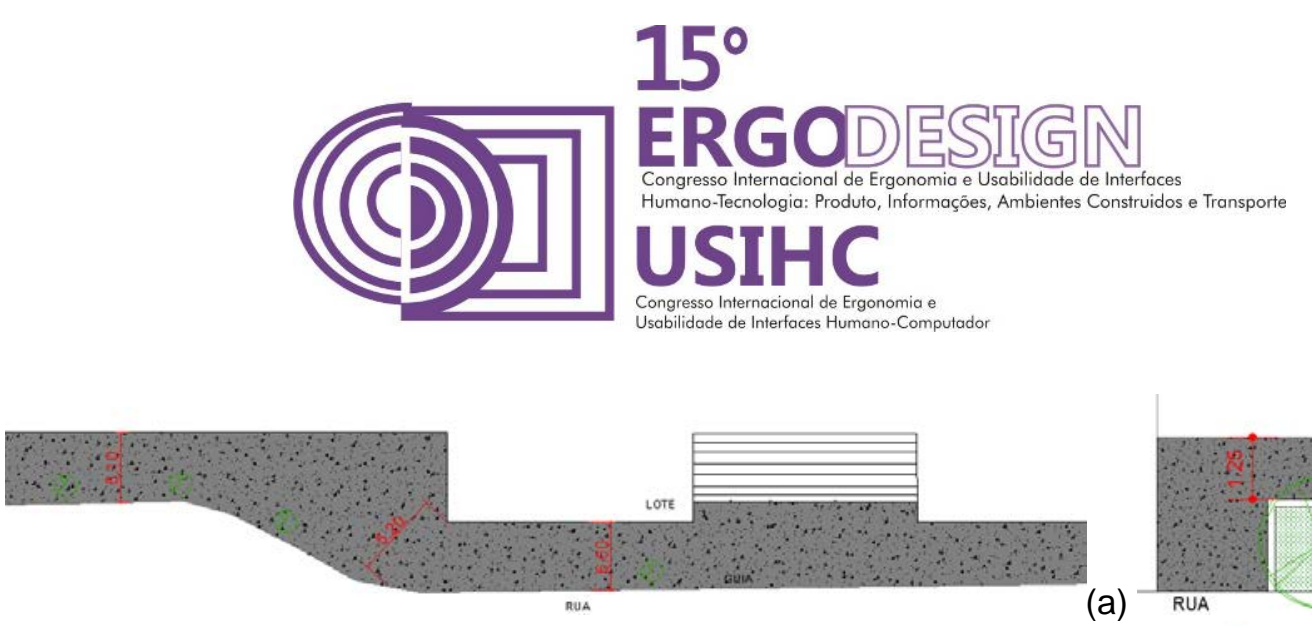

(a)

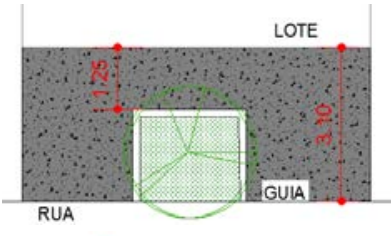

(b)
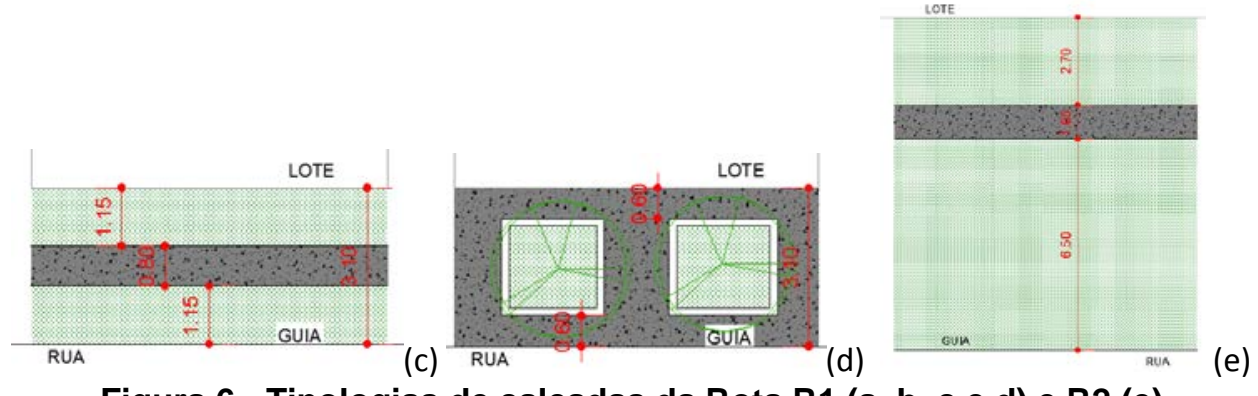

Figura 6 - Tipologias de calçadas da Rota R1 (a, b, c e d) e R2 (e)
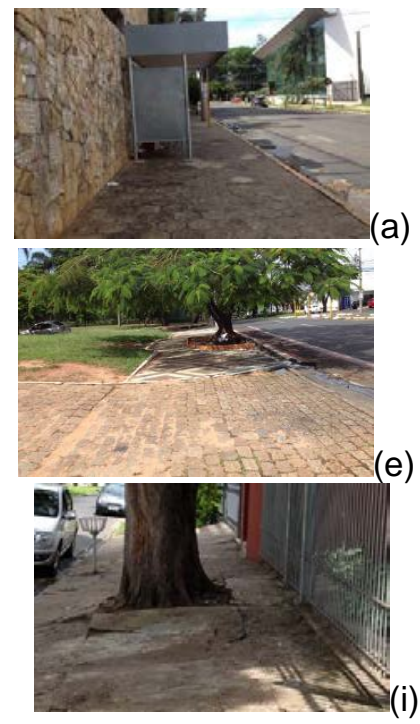

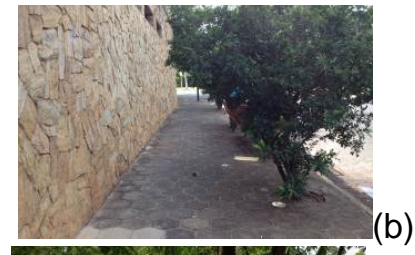

(b)

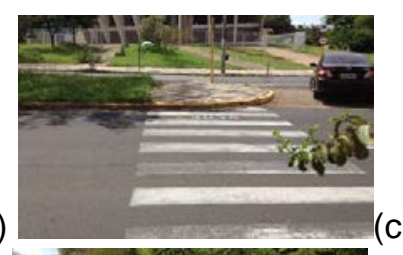

(c)
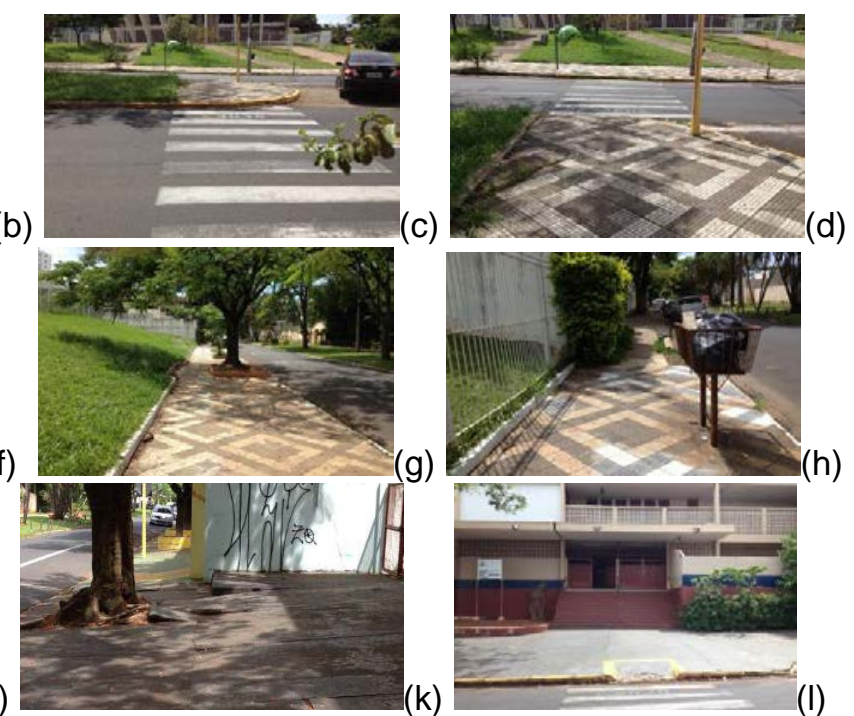

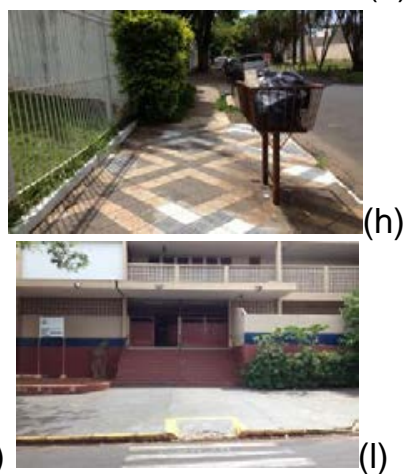

Figura 7 - Levantamento fotográfico Rota R1

Além da tipologia, os dois trajetos foram analisados individualmente, tendo como referência os temas e indicadores apresentados no item Metodologia. $O$ primeiro Tema avaliado correspondeu à Qualidade de Conforto das calçadas e seus respectivos Indicadores.

Analisando o tema "Qualidade de conforto" das calçadas na Rota R1 com relação ao indicador largura efetiva (faixa livre) observamos que as calçadas são extremamente estreitas; em três lotes dos seis pertencentes a esse trajeto, encontramos dimensões mínimas de 0,60m (Figuras $6 \mathrm{~d}, 7 \mathrm{i}$ e $7 \mathrm{j}$ ) ou $0,80 \mathrm{~m}$ (Figuras $6 \mathrm{c}$ e $7 \mathrm{~h}$ ), largura inadequada ao trânsito de pedestres; pois de acordo com a NBR 9050 a largura mínima recomendável é de 1,50m e o mínimo admissível é 1,20m (ABNT, 2004); os tipos de pisos sofrem variação de material (bloco sextavado, ladrilho hidráulico, paralelepípedo de pedra e concreto), a maioria possui superfícies rugosas, sendo 


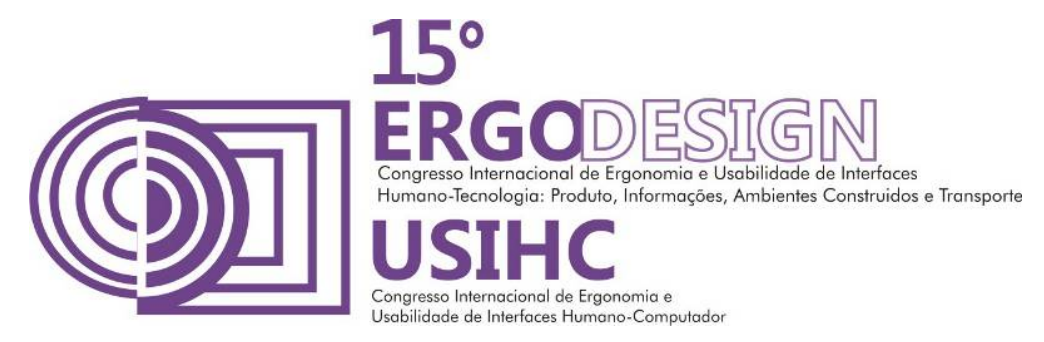

apenas um pequeno trecho de paralelepídeo escorregadio; o estado de conservação das calçadas é razoável, existem dois trechos com a superfície quebrada e com buracos devido às raízes de árvores. Salienta-se que a calçada de ladrilho hidráulico foi reformada há pouco tempo e que sua situação fica degradável em períodos de chuva por conta de enxurradas, Figuras $8 \mathrm{a}$ e 8b. A Figura 8c apresenta a situação que pode comprometer a segurança dos pedestres, pois as bocas de lobo estão com as tampas semiabertas.
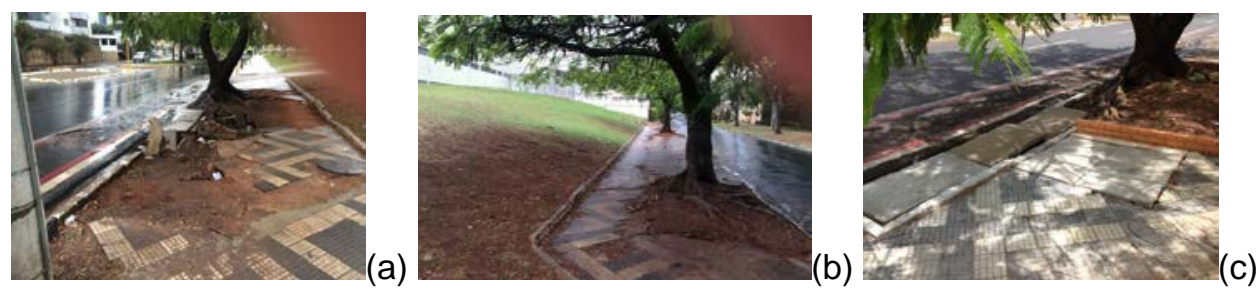

Figura 8 - Situação das calçadas da Rota R1 em períodos de chuva (a e b) e bueiros com tampa semiaberta (c)

As inclinações longitudinais estão dentro das normas técnicas. Analisando a inclinação transversal, apenas em dois trechos foram encontradas inclinações superiores a 3\% (Figura 7i e 7k). Com relação ao desnível o trecho todo está nivelado.

Em relação à "Qualidade da segurança da calçada" da Rota $R 1$, o item iluminação é adequado na travessia na Avenida 1, pois contém um poste de iluminação com três lâmpadas, porém o restante do trajeto é pouco iluminado. Na Rua 3 os postes de iluminação estão nas calçadas do outro lado da rua e além disso o porte da copa das árvores aumenta as sombras nas calçadas durante o período noturno. A arborização não tem manutenção o que prejudica a altura livre mínima de 2,10m (ABNT, 2004) para passagem de pedestres em algumas calçadas, como nas Figuras 7b e 7f. O mobiliário urbano, excetuando-se a vegetação, é instalado mais próximo à guia, entretanto, como a vegetação também deve ser instalada na faixa de mobiliário e por haver vegetação no meio da largura da calçada esse item é considerado inadequado (Figuras 6d, 7i e 7j).

$\mathrm{Na}$ "Qualidade de segurança durante a travessia", no caso dessa rota na travessia da Avenida 1: há sinalização horizontal como faixas de pedestres; mas não há sinalização vertical; nem rampas. A visão de aproximação dos veículos é prejudicada pela vegetação, não há semáforos.

A próxima etapa consistiu em analisar a segunda Rota $R 2$. Em relação ao Tema "Qualidade de conforto", a largura efetiva da maioria das calçadas da Rota R2 é um pouco maior do que no trajeto anterior, atingiram até $1,05 \mathrm{~m}$ de largura, porém ainda não atende a largura mínima admissível pela Norma NBR 9050 que é de de 1,20m (ABNT, 2004), como mostram as Figuras $6 e, 9 c, 9 d, 9 e$ e 9f, apenas a última calçada da rota, Figura $9 f$ em frente ao muro pintado de vermelho, tem a largura efetiva dentro da norma técnica, com 2,50m de largura. Com relação ao tipo de piso, estes em geral não são escorregadios, pois na maioria tem revestimento de concreto, apenas um lote é de paralélepipedo o que torna parte do percurso escorregadio. Com relação ao estado de conservação, as superfícies desta rota são um pouco melhor do que os da Rota R1, entretanto também apresentam superfícies irregulares e mal conservadas como 


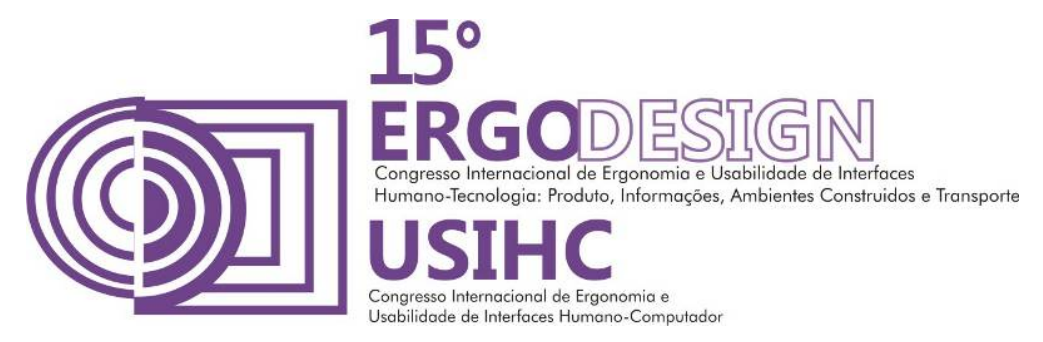

mostram as Figuras 9d e 9e. As inclinações longitudinais e as inclinações transversais estão adequadas. Foi encontrado apenas um desnível logo após o Ponto 3 (Figura 9b).
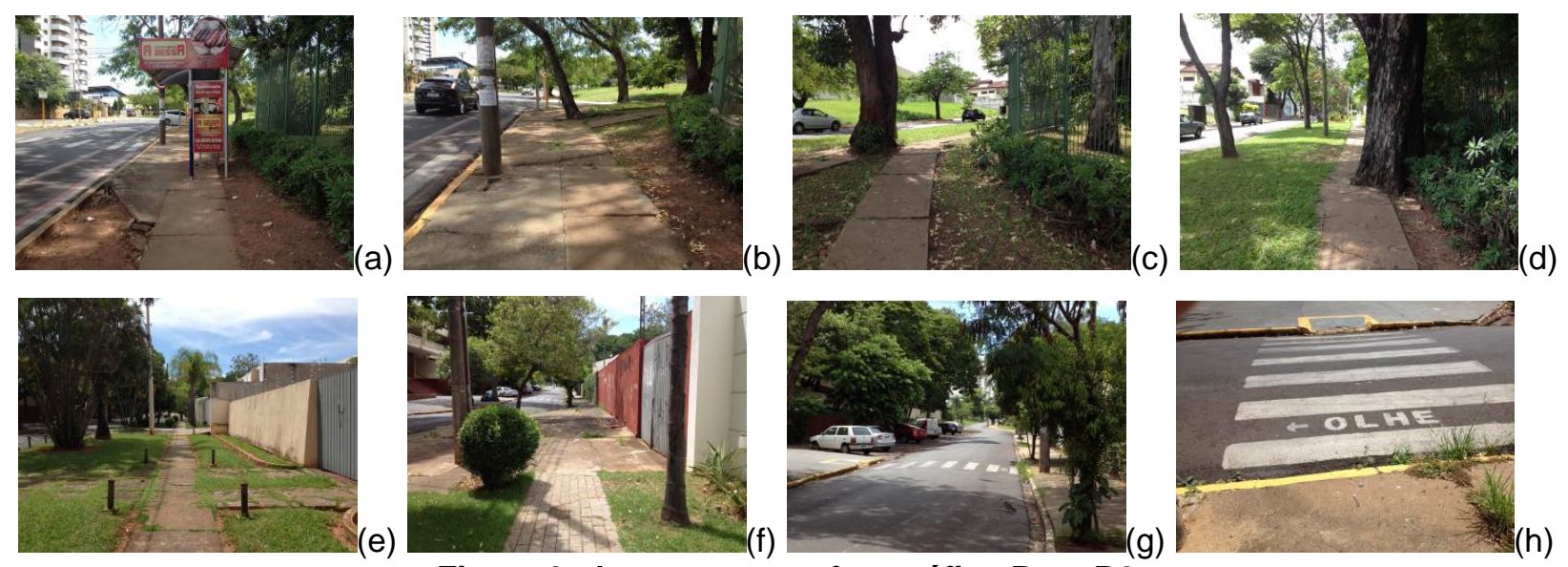

Figura 9 - Levantamento fotográfico Rota R2

Em relação ao tema "Qualidade da segurança da calçada" na Rota R2, verificou-se sobre a iluminação que apesar dos postes de iluminação estarem locados ao lado da largura efetiva da calçada, ou seja, praticamente no meio da largura da calçada, Figura 9d, 9e e 9f, o primeiro trecho entre o ponto de parada e o final do primeiro lote, Figura 9d, fica escuro devido à distância entre o poste da esquina e o primeiro poste da Rua 3, entretanto, chegando mais próximo à escola o espaçamento entre os poste diminui tornando o local um pouco mais iluminado. A arborização existente praticamente não prejudica quase a totalidade do percurso, por existir uma faixa de mobiliário bem larga com 6,50 de largura, com exceção do trecho apresentado na Figura 9d, onde o tronco da árvore está ocupando metade da faixa livre disponível à circulação. Dessa forma, somente nesse trecho o mobiliário urbano obstrui a calçada.

Para a análise do tema "Qualidade de segurança durante a travessia" da Rota R2 escolheu-se o trecho localizado em frente à escola. Foi encontrada sinalização horizontal, mas a sinalização vertical não existe. Encontrou-se uma rampa no lado oposto à calçada da Rota R2, ou seja, na Rota R1, com superfície irregular. A vegetação e poste de iluminação dificultam a visualização de aproximação dos veículos e não há semáforos para pedestres. Há sinalizações horizontal e vertical, avisando a proximidade da área escolar, Figura 10a e 10b.
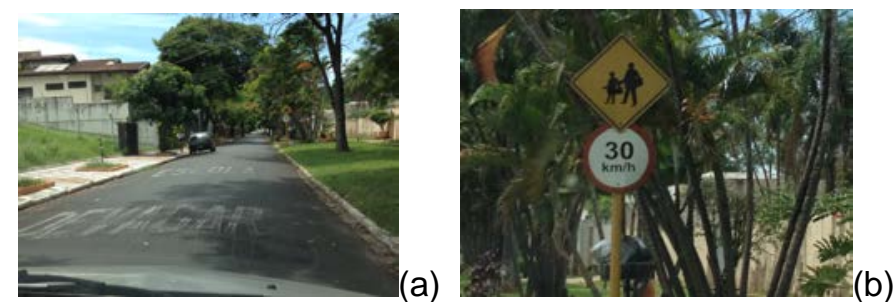

Figura 10 - Sinalização horizontal (a) e vertical (b) de proximidade de escola

A Tabela 2 apresenta um quadro resumo com a situação de cada um dos indicadores para 


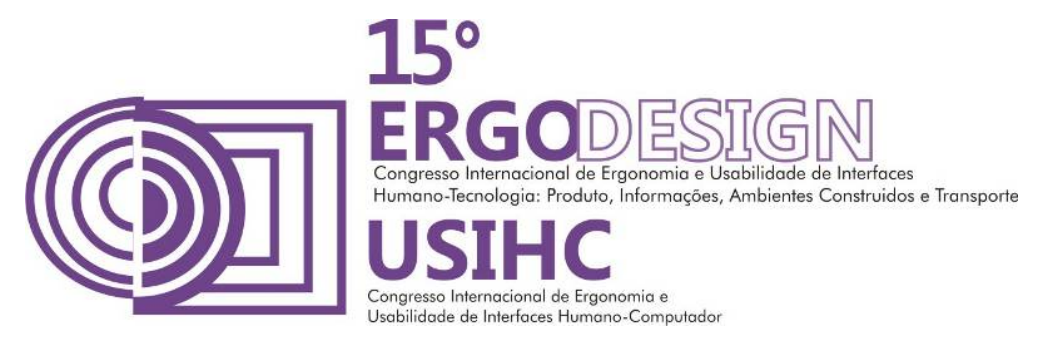

cada rota analisada.

Tabela 2. Quadro resumo dos problemas de microacessibildiade que afetam o trajeto à escola

\begin{tabular}{|c|c|c|c|}
\hline \multicolumn{2}{|r|}{ Indicadores de Microacessiblidade } & Rota - R1 & Rota-R2 \\
\hline \multirow{6}{*}{ 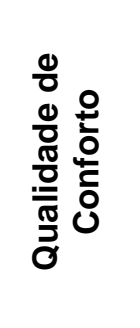 } & Largura efetiva & Inadequado & Inadequado \\
\hline & Tipo de piso - escorregadio & Inadequado & Inadequado \\
\hline & Estado de conservação da superfície do piso & Inadequado & Inadequado \\
\hline & Inclinação longitudinal & Adequado & Adequado \\
\hline & Inclinação transversal & Inadequado & Adequado \\
\hline & Desnível & Adequado & Inadequado \\
\hline \multirow{3}{*}{ 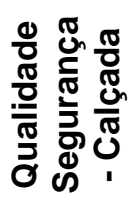 } & Iluminação & Inadequado & Inadequado \\
\hline & Arborização & Inadequado & Inadequado \\
\hline & Mobiliário Urbano - calçadas obstruídas & Inadequado & Inadequado \\
\hline \multirow{6}{*}{ 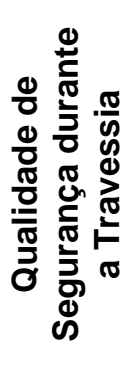 } & Sinalização horizontal & Adequado & Adequado \\
\hline & Sinalização vertical & Não há & Não há \\
\hline & Rampa & Não há & Inadequado \\
\hline & $\begin{array}{l}\text { Visão de aproximação dos veículos na } \\
\text { travessia }\end{array}$ & Inadequado & Inadequado \\
\hline & Semáforo para pedestres & Não há & Não há \\
\hline & Tempo de semáforo & Não há & Não há \\
\hline
\end{tabular}

O Tema "Qualidade de conforto" apresentou empate em $66,67 \%$ dos itens analisados, ou seja, apenas dois itens desse rol de indicadores estão implantados de forma adequada - a inclinação longitudinal nas duas rotas; o desnível na Rota R1 e a inclinação transversal na Rota R2. Com relação ao Tema "Qualidade da segurança da calçada" 100\% dos indicadores estão inadequados nas duas rotas. Analisando o Tema "Qualidade de segurança durante a travessia" $16,67 \%$ dos indicadores estão inadequados na Rota R1 e 33,33\% dos indicadores na Rota R2, nas duas rotas o item visão de aproximação dos veículos na travessia foi considerado inadequado e a rampa na Rota R2. Ressalta-se que nesse Tema na Rota R1 66,67\% dos itens não existem para análise, enquanto na Rota R1 esse valor cai para 50\%. Considerando as 3 temáticas, a quantidade de itens adequados nas duas rotas empatou em $20 \%$ e os itens inadequados foram 53.33\% na Rota R1 e 60\% na Rota R2, portanto a Rota R1 demonstra-se minimamente melhor do que a Rota R2os $20 \%$ restantes referem-se aos itens inexistentes para análise.

De forma geral, os aspectos mais relevantes que não encontram-se adequados nas duas rotas são da "Qualidade de conforto": largura efetiva da calçada, que prejudica a circulação de mais de uma pessoa nesse espaço e o estado de conservação da superfície do piso que em sua maior parte decorre das raízes de árvores de grande porte; em "Qualidade da segurança da calçada": também relacionada à vegetação que foi plantada na faixa livre de circulação de pedestres nas calçadas tornando as duas rotas obstruídas; enquanto na "Qualidade de 


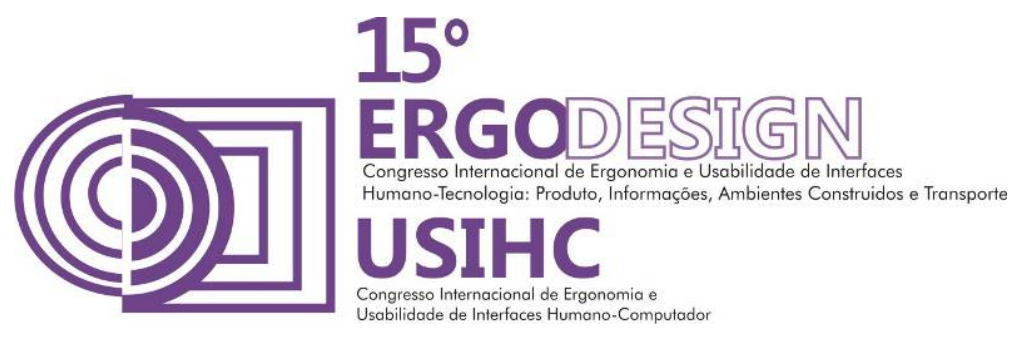

segurança durante a travessia": inexistência de rampas de rebaixamento das calçadas que impossibilita a mobilidade de pessoas com deficiência e a obstrução da visão de aproximação dos veículos por copas de árvore de pequeno porte ou falta de manutenção das copas.

De acordo com os resultados obtidos através da análise dos indicadores de microacessibilidade nos trajetos compreendidos entre os pontos de parada e o entorno do edifício escolar estudado podemos afirmar que há um comprometimento na segurança e conforto dos pedestres/usuários da escola, em função da inexistência de infraestrutura adequada, associada à falta de aplicação das normas técnicas e da legislação Municipal, Estadual e Federal, sobre acessibilidade.

\section{CONSIDERAÇÕES FINAIS}

Os Indicadores de acessibilidade urbana utilizados para avaliar o entorno de áreas escolares permitiu a identificação de vários problemas urbanos relacionados à microacessibilidade na área escolar, que podem interferir na qualidade espacial, no conforto e na segurança dos usuários.

Em relação aos problemas identificados destacamos como prioritários para tornar as duas rotas mais seguras: 1. Adequação da largura efetiva das calçadas; 2. Manutenção dos pisos para torná-los regulares, nivelados e não escorregadios; 3. Construção de rampas de travessia atendendo às normas vigentes; 4. Manutenção regular das copas das árvores.

Considerando estes resultados, pode-se afirmar que os indicadores propostos visam contribuir para análises semelhantes, que contribuam para: i) compor um sistema de Indicadores de Acessibilidade Urbana para o entorno de áreas escolares, que podem auxiliar os gestores locais na tomada de decisão, no planejamento e monitoramento destes espaços, ii) contribuir para a realização de um amplo diagnóstico no entorno dessas áreas, a fim de propor diretrizes que podem ser implementadas a curto e médio prazo, tornando o espaço mais acessível e seguro, e iii) contribuir para a formulação de programas, projetos e políticas municipais, que visem proporcionar melhor qualidade de vida aos pedestres.

A metodologia aplicada mostrou-se relevante para esta avaliação, pois retratou fielmente os problemas associados à infraestrutura do pedestre encontrados neste local, entretanto sugerese a inclusão de outros indicadores para uma avaliação mais completa.

\section{REFERÊNCIAS BIBLIOGRÁFICAS}

ASSOCIAÇÃO BRASILEIRA DE NORMAS TÉCNICAS. NBR 9050 - Acessibilidade de pessoas com deficiência a edificações, espaço, mobiliário e equipamentos urbanos. Rio de Janeiro. 2004.

BIANCHI, I.M. A microacessibilidade em vias urbanas estruturais: o caso da $3^{\text {a }}$ perimetral de Porto Alegre. Dissertação (Mestrado). Pós-Graduação em Desenvolvimento Urbano e Regional. UFRGS. Porto Alegre. 2011.

BRASIL. Decreto Lei 5.296, de 2 de dezembro de 2004. Regulamenta as Leis nos 10.048, de 8 de novembro de 2000, que dá prioridade de atendimento às pessoas que especifica, e 10.098, de 19 de dezembro de 2000, que estabelece normas gerais e critérios básicos para a promoção da acessibilidade das pessoas portadoras de deficiência ou com mobilidade reduzida, e dá outras providências. Brasília: Senado Federal. 2004. 


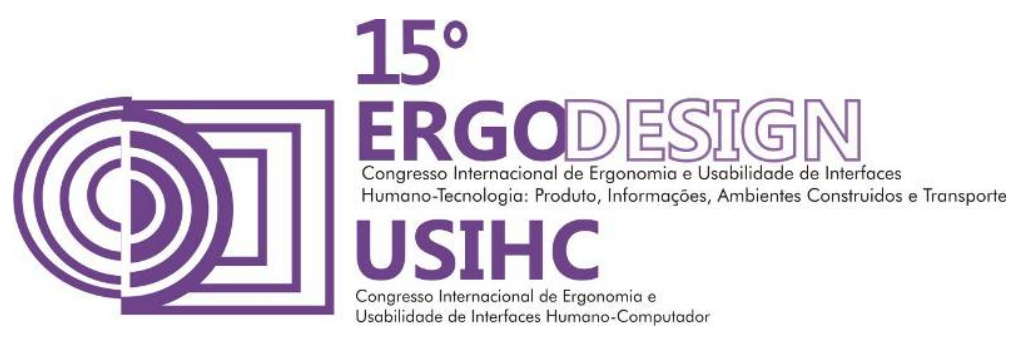

BRASIL. Ministério das Cidades. Brasil Acessível. Programa brasileiro de acessibilidade urbana. Cadernos 1, 2, 3, 4, 5 e 6. Secretaria Nacional de Transporte e da Mobilidade Urbana. Brasília. 2007.

CAMPÊLO, A.E.P. Proposição de modelo para escolha de rotas urbanas acessíveis considerandose os critérios de microacessibilidade para as pessoas com deficiência física motora. Dissertação (Mestrado). Programa de Pós-Graduação em Engenharia de Transportes. UF Ceará. Fortaleza. 2011.

COLLINS, D. C. A. \& KEARNS, R. A. Geographies of inequality: Child pedestrian injury and walking school buses in Auckland, New Zealand. Social Science \& Medicine, n. 60: p. 61-69. 2005.

FERREIRA, M. A.; SANCHES, S. P. Proposal of a sidewalk accessibility index, Journal of Urban and Environmental Engineering 1(1). 2007. 1-9.

Instituto Brasileiro de Geografia e Estatística - IBGE. Informações estatísticas do Município de Bauru, 2010. Disponível em: http://cidades.ibge.gov.br/xtras/perfil.php?lang=\&codmun=35060 0\&search=saopaulo|bauru>. Acesso em: 29 set. 2013.

IPINGBEMI, O. \& AIWORO, A.B. Journey to school, safety and security of school children in Benin City, Nigeria. Transportation Research, Part F, n. 19: p. 77-84. 2013.

KEPPE Junior, C.L.G. Formulação de um indicador de acessibilidade das calçadas e travessias. Dissertação (Mestrado) Engenharia Urbana. Universidade Federal de São Carlos. 2007.

LITMAN, Todd. Traffic, Mobility and Accessibility. In: Measuring Transportation. Victoria Transport Policy Institute (VTPI). 2008. Disponível em: www.vtpi.org

MAGAGNIN, R. C. Cidades Acessíveis: o planejamento da infraestrutura para a circulação de pedestres. In: Maria Solange G. de Castro Fontes, Norma Regina T. Constantino e Luis Cláudio Bittencourt (eds). Arquitetura e Urbanismo: novos desafios para o século XXI. Bauru: Canal 6. 2009.

MAGAGNIN, R.C.; SALCEDO, R.F.B.; FONTES, M.S.G.C. Urban sustainability in pedestrian street in downtown areas: Case study of Bauru - Brazil, in: Proceedings of Passive and Low Energy Architecture - PLEA 2012 - 28th Conference, Opportunities, Limits \& Needs Towards an Environmentally Responsible Architecture, Lima, Peru, pp. 1-6. 2012.

MENDONZA, J. A.; WATSON, K.; CHEN, T.; BARANOWSKI, T.; NICKLAS, T. A.; USCANGA, D. K.; HANFLING, M. J. Impact of a pilot walking school bus intervention on children's pedestrian safety behaviors: A pilot study. Health \& Place, n.18: p. 24-30. 2012.

MÜLLER, V. R.; ARRUDA, F. M. O trânsito e o transporte na cidade: caminhos propostos pelas crianças para uma maior mobilidade em Maringá, PR. Série-Estudos - Periódico do Programa de PósGraduação em Educação da UCDB, Campo Grande-MS, n. 35, p. 117-135, jan./jun. 2013.

STEWART, O.; MOUDON, A. V. \& CLAYBROOKE, C. Common ground: Eight factors that influence walking and biking to school. Transport Policy, n.24: p. 240-248. 2012.

UNICEF - Fundo das Nações Unidas para a Infância. Convenção sobre os direitos da criança. 1989.

YEUNG, J.; WEARING, S. \& HILLS, A. P. Child transport practices and perceived barriers in active commuting to school. Transportation Research, Part A, n. 42: p. 895-900. 2008. 